\title{
Produção animal e retorno econômico da suplementação em pastagem de aveia e azevém
}

\author{
Animal production and economic return in a supplementated oats/ \\ ryegrass mixture
}

\author{
Marta Gomes da Rocha ${ }^{1}$ João Restle ${ }^{2}$ Alcides Pilau $^{3}$ \\ Davi Texeira dos Santos ${ }^{3}$
}

\section{RESUMO}

$O$ experimento avaliou a resposta animal e o retorno econômico do uso da suplementação energética em pastagem de aveia preta (Avena strigosa Schreb) + azevém anual (Lolium multiflorum Lam). Os tratamentos foram: STP - Suplementação, durante todo o período de utilização da pastagem; SAS- Suplementação até final de setembro; SSSem suplementação. O sistema de pastejo foi o contínuo com lotação variável. O suplemento utilizado foi o grão de sorgo em quantidade variável para manter a mesma quantidade de massa de forragem em todos os tratamentos. O ganhos de peso médios diários por animal (GMD) foram superiores nos tratamentos $S T P$ e $S A S, 0,716$ e $0,710 \mathrm{~kg}$, respectivamente, em relação ao obtido no tratamento $S S(0,580 \mathrm{~kg}) . \quad A$ suplementação possibilitou maior carga animal. A produção animal por hectare foi maior em STP, $627 \mathrm{~kg} \mathrm{ha}^{-1}$ de PV, sendo $75 \%$ superior aos $359 \mathrm{~kg} \mathrm{ha}^{-1}$ de PV do SS. A suplementação não afetou a condição corporal dos animais. $O$ custo total e a receita líquida foram de 775,42/165,08, 605,75/204,25e $367,35 / 204,92 R \$ h^{-1}$ para STP, SAS e SS, respectivamente. $O$ uso exclusivo da pastagem e a suplementação, até o final de setembro, resultaram em maior retorno financeiro direto.

Palavras-chave: carga animal, ganho de peso, sorgo, bezerras de corte.

\section{ABSTRACT}

The experiment evaluated the animal response and economic return of energetic supplementation in oat (Avena strigosa Schreb) plus Italian ryegrass (Lolium multiflorum Lam) pasture. The treatments were: STP-Supplementation during the entire pasture cycle; SAS- Supplementation until the end of September and SS-No supplement. The continuous grazing system with variable stocking rate was used. The supplement utilized, with different quantities, was ground sorghum in order to maintain the same herbage mass for all treatments. Live weight daily gain was higher in STP and SAS, 0.716 and 0.710 $\mathrm{kg}$, respectively than $0.580 \mathrm{~kg}$ in $\mathrm{SS}$. The stocking rate was greater with supplements. The higher weight gain per hectare was at STP (627 kg), 75\% higher than no supplement treatment, $359 \mathrm{kgha}$ of LW. No significant effects on body condition score of treatments was recorded. The total cost and the net income were $775.42 / 165.08,605.75 / 204.25$ and 333.58/204.92 R\$ha for STP, SAS and SS, respectively. No supplements and the use of supplementation until the end of September resulted in higher economic return.

Key words: stocking rate, weight gain, sorghum, beef heifers

\section{INTRODUÇÃo}

As pastagens cultivadas de inverno, como a aveia e o azevém, são usadas, no Rio Grande do Sul, para permitir um desenvolvimento adequado dos animais durante o período de paralisação do crescimento da pastagem natural. Tratando-se de fêmeas de corte, o ganho de peso realizado nesta ocasião oportunizaria a redução de sua idade à puberdade. Um custo adicional, no entanto, é agregado ao sistema de produção da propriedade para a

\footnotetext{
${ }^{1}$ Engenheiro Agrônomo, Doutor, Professor do Departamento de Zootecnia, Centro de Ciências Rurais (CCR), Universidade Federal de Santa Maria (UFSM), Camobi, 97105-900, Santa Maria, RS, Brasil. E-mail: mrocha@ccr.ufsm.br. Autor para correspondência

${ }^{2}$ Engenheiro Agrônomo, PhD, Professor do Departamento de Zootecnia, CCR, UFSM

${ }^{3}$ Zootecnista, Estudante do Curso de Pós-graduação em Zootecnia da UFSM. Bolsista CAPES
} 
implantação e manutenção destas pastagens. O conhecimento do potencial biológico das espécies forrageiras utilizadas torna-se fundamental para estabelecer um planejamento forrageiro adequado, permitindo assim uma melhor relação entre produtividade e economicidade.

A suplementação energética, em pastagens de alta digestibilidade, é uma alternativa para aumentar a velocidade de crescimento dos animais através de um melhor balanceamento dos nutrientes da dieta e de um aumento do consumo total de matéria seca. A substituição de parte do consumo de forragem pelo consumo de suplemento pode elevar a capacidade de carga até valores que, sem redução acentuada do ganho por indivíduo, possibilitem melhorar a produção animal por unidade de área. $\mathrm{O}$ custo do suplemento, no entanto, restringe com freqüência seu uso a quantidades limitadas nos momentos mais oportunos.

Do ponto de vista biológico, novilhas de corte acasaladas aos 24 meses de idade não requerem altas taxas de ganho de peso nos períodos de inverno durante a recria. Do ponto de vista econômico, com essa categoria, o produtor precisa manter uma carga animal alta na pastagem, com um desempenho individual satisfatório. Como a pastagem não cresce de maneira uniforme, durante o seu ciclo de produção, a suplementação energética, quando em quantidade variável, pode ser uma ferramenta para tentar manter constante o número de animais durante o período produtivo da pastagem. Este trabalho foi conduzido com o objetivo de verificar o efeito da suplementação energética em diferentes períodos do ciclo da pastagem de aveia e azevém sobre a produção animal e avaliar a viabilidade econômica desta técnica na recria de bezerras de corte no primeiro inverno pós-desmama.

\section{MATERIALE MÉTODOS}

$\mathrm{O}$ experimento foi conduzido em área do Departamento de Zootecnia da Universidade Federal de Santa Maria, situada na Depressão Central do RS, com altitude de $95 \mathrm{~m}, 29^{\circ} 43^{\prime}$ de latitude Sul e $53^{\circ} 42^{\prime}$ de longitude Oeste. O clima da região é Cfa (Subtropical úmido) conforme a classificação de Köppen (MORENO, 1961).

Os tratamentos foram: STP- Pastagem de aveia e azevém com animais recebendo suplementação energética durante todo o período de pastejo; SASPastagem de aveia e azevém com animais recebendo suplementação energética até o final de setembro; SSPastagem de aveia e azevém, sem suplementação. O delineamento experimental foi o inteiramente casualizado, com três repetições, com área de um hectare cada uma. Os dados foram submetidos à análise de variância e as médias comparadas pelo teste de Tukey em nível de $5 \%$ de probabilidade de erro.

Foram utilizadas bezerras com idade média inicial de oito meses, peso médio inicial de $117 \mathrm{~kg}$ e condição corporal média de 2,7, das raças Charolês, Nelore e suas cruzas. O baixo peso inicial das bezerras foi decorrente de sistemas alimentares diferenciados por ocasião de sua desmama aos 60 dias até os sete meses de idade. Os animais foram mantidos em pastagem de aveia preta mais azevém sob pastejo contínuo com massa de forragem (MF) média de $1000 \mathrm{~kg}$ $\mathrm{ha}^{-1}$ de MS. O suplemento utilizado foi o grão de sorgo moído, e a quantidade oferecida foi variável, regulada semanalmente, visando a conservar a mesma MF em todos os tratamentos. Para manter a MF pretendida foram utilizados animais reguladores e a suplementação foi fornecida observando-se o intervalo compreendido entre 0,8 a $1,8 \%$ do peso vivo (PV). O suplemento foi fornecido em uma única vez ao dia, às treze horas, quando em níveis inferiores ou iguais a $1,5 \%$ do PV. Em níveis superiores, o fornecimento foi realizado em duas vezes, às oito $\mathrm{e}$ às treze horas.

A pastagem foi implantada pelo sistema convencional, usando-se inicialmente a grade aradora e, em seguida, duas gradagens leves, com grade niveladora. A semeadura foi realizada a lanço em 01/ 04/1998, utilizando-se $85 \mathrm{~kg} \mathrm{ha}^{-1}$ de aveia preta e $35 \mathrm{~kg}$ ha ${ }^{-1}$ de azevém anual. A adubação de formação da pastagem foi de 200 $\mathrm{kg} \mathrm{ha}^{-1}$ da fórmula 5-30-15 e, em cobertura, foram utilizados $120 \mathrm{~kg} \mathrm{ha}^{-1}$ de N sob a forma de uréia, em três aplicações (31/05, 26/07 e 26/09). O pastejo foi iniciado após 76 dias de estabelecimento e o período total de utilização foi de 137 dias, de 15/06 a $30 / 10$.

As avaliações da MF foram realizadas a cada quatorze dias, pela técnica de dupla amostragem (BROWN, 1954). A forragem proveniente das amostras cortadas foi homogeneizada e, posteriormente, uma amostra composta por período foi utilizada para a determinação do teor de matéria seca (MS) e proteína bruta (PB). Usando-se a metodologia de TILLEY \& TERRY (1963) foi determinada a digestibilidade in vitro das matéria seca e orgânica (DIVMS e DIVMO).

As pesagens dos animais foram realizadas com jejum prévio de seis horas. O controle de endo e ecto parasitas seguiu o calendário do Setor de Bovinocultura de Corte do Departamento de Zootecnia - UFSM, e as vacinações seguiram o calendário da Secretaria da Agricultura do RS.

Todos os animais receberam sal comum e monensina sódica nas quantidades de 30 e $1 \mathrm{~g} / \mathrm{animal} /$ dia, respectivamente. Para a avaliação da condição 
corporal foi utilizada uma adaptação da metodologia de LOWMAN et al. (1973), variando de 1,0 (muito magro) a 5,0 (muito gordo).

O ganho de peso médio diário (GMD) dos animais por período e por tratamento foi obtido pela diferença de peso vivo entre as pesagens dos animais 'testers' no início e no final do mesmo, dividido pelo número de dias de intervalo entre as pesagens. A carga animal média (CA), por período, em $\mathrm{kg} \mathrm{ha}^{-1}$ de $\mathrm{PV}$, foi calculada pelo somatório do produto do peso médio de cada animal pelo número de dias que esse permaneceu na área dividido pelo número de dias do período. O ganho de $\mathrm{PV} \mathrm{ha}^{-1}$, em cada período, foi obtido pela soma do ganho total dos animais "testers" com o produto do GMD dos 'testers' pelo número de dias que cada animal regulador permaneceu na área.

Os cálculos de custos foram feitos por meio de planilha eletrônica do programa EXCEL, versão 2000. Consideraram-se como 'custos básicos', os investimentos feitos para a implantação e a manutenção da pastagem, iguais em todos os tratamentos. Os custos determinados pela suplementação foram denominados 'custos adicionais' e referem-se ao suplemento e seu fornecimento, mão-de-obra adicional, cochos, sal, monensina sódica e vermífugos. O custo total de cada tratamento foi composto pelos custos básicos mais os custos adicionais. Os preços para o cálculo de custos e receitas foram obtidos a partir de uma pesquisa de mercado efetuada durante a primeira quinzena do mês de outubro de 2000 . O cálculo da renda bruta, em cada tratamento, foi efetuado multiplicando-se o ganho de peso vivo por hectare pelo preço médio pago pelo $\mathrm{kg}$ vivo da bezerra na primeira quinzena do mês de outubro de 2000. Deste valor, foi subtraído o custo total por hectare no período, obtendo-se a receita líquida por tratamento.

\section{RESULTADOS E DISCUSSÃO}

Na tabela 1, encontram-se os valores determinados na pastagem de aveia e azevém anual para os parâmetros: massa de forragem, teor de proteína bruta e DIVMO, média dos tratamentos por período. Na tabela 2, encontram-se os resultados referentes ao ganho de peso médio diário (GMD) dos animais por tratamento. O GMD foi maior nos tratamentos suplementados em relação ao tratamento SS em 19 e $22,4 \%$ para SAS e STP, respectivamente. Estes percentuais quantificam o efeito aditivo do suplemento no desempenho individual dos animais, também verificado quando da retirada do suplemento no final de setembro, quando o GMD dos animais suplementados foi, em média, $17 \%$ superior aos não suplementados $(0,690 \times 0,460 \mathrm{~kg})$. Este desempenho pode ser explicado pelo maior aporte energético advindo do suplemento, pois o sorgo apresentou energia metabolizável (EM) de 2,94Mcal kg-1 enquanto a pastagem apresentava $1,98 \mathrm{Mcal} \mathrm{kg}^{-1}$. Nos períodos intermediários (12/07 a 03/10), no tratamento não suplementado, quando a MF decresceu de 1200 para $800 \mathrm{~kg} \mathrm{ha}^{-1}$ de MS (tabela 1), mesmo com EM média de 2,59 Mcal kg-1, a baixa disponibilidade de forragem da pastagem não possibilitou a colheita de uma quantidade de matéria seca para assegurar um bom desempenho animal. As exigências nutricionais de fêmeas desta categoria, para ganhos médios diários de $0,6 \mathrm{~kg}$, conforme o NATIONAL RESEARCH COUNCIL (1996), quanto ao percentual de PB e energia líquida são de 11,4 e 2,32Mcal $\mathrm{dia}^{-1}$, respectivamente. O consumo máximo de MS estimado pelo NRC, para estes animais, é de $3,75 \mathrm{~kg} \mathrm{dia}^{-1}$. Os animais suplementados mantiveram, durante todo o ciclo da pastagem, GMD próximo a $0,6 \mathrm{~kg} \mathrm{dia}^{-1}$, pois a substituição do consumo de forragem por suplemento manteve o nível energético fornecido e o decréscimo no percentual de PB da dieta foi compensado pelo aumento no consumo total de MS advindo da suplementação. Assim, os fatores responsáveis pelo efeito da suplementação no GMD durante cada segmento do experimento, podem envolver o decréscimo no consumo e na qualidade da forragem no decorrer do período e sua interação com o teor de PB do grão de sorgo.

No período total de utilização da pastagem, os GMD ficaram abaixo dos observados por

Tabela 1- Massa de forragem (MF), teor de proteína bruta (PB) e digestibilidade in vitro da matéria orgânica (DIVMO), média dos tratamentos por período, em aveia mais azevém sob pastejo contínuo com bezerras de corte submetidas a diferentes períodos de suplementação energética.

\begin{tabular}{|c|c|c|c|c|c|}
\hline \multirow[t]{4}{*}{ Parâmetros } & \multicolumn{5}{|c|}{ Período } \\
\hline & $15 / 06$ & $12 / 07$ & $09 / 08$ & $09 / 09$ & $04 / 10$ \\
\hline & a & a & a & $\mathrm{a}$ & $\mathrm{a}$ \\
\hline & $11 / 07$ & $08 / 08$ & 08/09 & $03 / 10$ & $12 / 11$ \\
\hline MF $\left(\mathrm{kg} \mathrm{ha}^{-1}\right.$ de matéria seca) & 1236 & 886 & 760 & 945 & 1512 \\
\hline PB $(\%)$ & 13,0 & 13,5 & 16,5 & 14,0 & 11,0 \\
\hline DIVMO (\%) & 72,0 & 75,0 & 71,0 & 58,0 & 52,0 \\
\hline
\end{tabular}

Ciência Rural, v. 33, n. 3, mai-jun, 2003. 
Tabela 2- Ganho de peso médio diário (GMD), carga animal (CA), ganho de PV ha ${ }^{-1}$, consumo de suplemento (CS) e quantidade de suplemento necessária para obtenção de um $\mathrm{kg} \mathrm{ha}^{-1}$ adicional no ganho de PV em aveia e azevém sob pastejo contínuo com bezerras de corte submetidas a diferentes períodos de suplementação energética.

\begin{tabular}{|c|c|c|c|}
\hline \multirow[t]{2}{*}{ Parâmetro } & \multicolumn{3}{|c|}{ Suplementação ${ }^{1}$} \\
\hline & $\begin{array}{c}\text { Todo } \\
\text { período }\end{array}$ & $\begin{array}{c}\text { Final } \\
\text { setembro }\end{array}$ & Sem \\
\hline GMD (kg an. $\left.{ }^{-1} \mathrm{dia}^{-1}\right)$ & $0,716 \mathrm{a}$ & $0,710 \mathrm{a}$ & $0,580 \mathrm{~b}$ \\
\hline $\mathrm{CA}\left(\mathrm{kg} \mathrm{ha}^{-1}\right.$ de PV $)$ & $1120 \mathrm{a}$ & $985 \mathrm{a}$ & $708 \mathrm{~b}$ \\
\hline Ganho PV $\left(\mathrm{kg} \mathrm{ha}^{-1}\right)$ & $627 \mathrm{a}$ & $540 \mathrm{~b}$ & $359 \mathrm{c}$ \\
\hline C S $(\% \mathrm{PV})$ & 1,3 & 1,0 & -- \\
\hline kg supl. $\mathrm{kg}^{-1} \mathrm{PV}$ adicional & 7,3 & 7,6 & -- \\
\hline
\end{tabular}

${ }^{1}$ Médias não seguidas por mesma letra naa linha, diferem pelo teste de Tukey em nível de $5 \%$ de probabilidade de erro.

QUADROS (1987) e RESTLE et al. (1995) em pastagens de inverno, sem suplementação. Segundo ROCHA (1997), a substituição de forragem por suplemento pode chegar a um extremo em que o aporte líquido de nutrientes para o animal fica desbalanceado, possibilitando a redução na taxa de ganho de peso. MIERES (1997) cita que o consumo de quantidades elevadas de suplemento com alto teor de amido, como o sorgo, pode deprimir a digestibilidade da forragem, em particular da fração fibra, reduzindo, também, a sua ingestão.

O GMD observado nesta fase de recria, em animais de todos os tratamentos, no entanto, esteve dentro do intervalo entre 0,4 a $0,8 \mathrm{~kg} \mathrm{dia}^{-1}$, considerado por BERETTA \& LOBATO (1998) como necessário para que seja atingida, o mais cedo possível, a maturidade sexual de fêmeas de corte. No presente experimento, os pesos inicial e final foram de 115,9 e 214,0kg, 117,2 e $214,5 \mathrm{~kg}$ e 117,9 e 197,4kg, respectivamente, para STP, SAS e SS. Apesar do baixo peso vivo (PV) inicial das bezerras ao início do pastejo, os valores de PV observados, ao término do período experimental, podem ser considerados satisfatórios, pois, desse modo, podem estar aptas para o acasalamento aos 24 meses de idade. Admitindo que fêmeas atinjam a sua maturidade sexual com $65 \%$ do PV de vaca adulta, ou seja, $450 \mathrm{~kg}$, o GMD conseguido, no primeiro inverno, reduz a necessidade de ganhos médios superiores a $0,230 \mathrm{~kg} \mathrm{dia}^{-1}$ no segundo ano de vida dessas novilhas. Como, na estação estival, a pastagem natural no RS apresenta potencial de GMD entre 0,3 a $0,5 \mathrm{~kg}$ animal ${ }^{-1}$, o acasalamento das fêmeas, aos dois anos de idade torna-se um objetivo efetivamente fácil de ser alcançado. Neste trabalho, ficou evidenciado que o uso da suplementação pode possibilitar que um número maior de novilhas cheguem ao final do primeiro inverno com desenvolvimento satisfatório, aspecto relevante no manejo de reposição de fêmeas do rebanho.

$\mathrm{Na}$ tabela 2, encontram-se também os resultados de ganho de peso vivo ha ${ }^{-1}$ e carga animal, consumo médio diário de suplemento e quantidade de suplemento oferecida para a obtenção de um $\mathrm{kg}$ adicional no ganho de peso vivo ha-1 . No SS, foram obtidos $359 \mathrm{~kg} \mathrm{ha}^{-1}$ de PV, valor inferior aos $598 \mathrm{~kg}$ observados por RESTLE et al (1995). Diferenças nas condições climáticas, durante o período de utilização da pastagem, níveis diferenciados de adubação nitrogenada e da MF foram determinantes para ganhos de peso vivo inferiores no presente trabalho. Neste sentido, o tratamento STP possibilitou GPV ha ${ }^{-1}$ superior aos demais tratamentos, sendo $16 \%$ maior em relação ao SAS e 75\% superior ao SS. Foram fornecidos para STP e SAS, respectivamente, 7,3 e 7,6kg de suplemento para cada $\mathrm{kg}$ de ganho de peso vivo por hectare adicional em relação ao SS. Estas relações são mais eficientes que as encontradas por GÓMEZ et al. (1981), em pastagem de cevada com novilhos suplementados com sorgo moído a 0,7 e 1,2\% do PV, obtendo valores de 9,4:1 e 11,5:1, respectivamente. ASSMANN et al. (1999) usando grão de milho, encontraram $4,8 \mathrm{~kg}$ de suplemento para cada $\mathrm{kg}$ de ganho adicional. Os resultados obtidos no presente trabalho, no entanto, concordam com OFICIALDEGUI (1991), que afirma que sete a oito $\mathrm{kg}$ de grãos por $\mathrm{kg}$ de $\mathrm{PV}$ adicional representam um bom índice. Os incrementos no ganho de PV por hectare são decorrentes, principalmente, do aumento da carga animal ha-1 ${ }^{-1}$ proporcionado pelo uso da suplementação. $\mathrm{O}$ consumo de MS da pastagem decresce cerca de 0,5 a $0,9 \mathrm{~kg}$ para cada kg de grão consumido (ROCHA, 1997). A substituição de forragem por suplemento possibilitou, neste trabalho, incrementos de carga animal de 58 e $39 \%$ para STP e SAS, respectivamente, em relação a SS. Os níveis médios de suplementação foram de $1,3 \%$ do PV no STP e $1,02 \%$ do PV no tratamento SAS. FRIZZO et al. (2000), utilizando novilhas em pastagem de aveia mais azevém suplementadas com polpa cítrica mais farelo de arroz (1:1), com nível de suplemento de $0,7 \%$ do peso vivo, obtiveram um aumento de carga de $26 \%$, e com $1,4 \%$ do PV, $76 \%$ de incremento de carga animal em relação ao tratamento não suplementado. ASSMANN et al. (1999), utilizando três níveis de milho macerado, não encontraram diferenças para carga animal nestes tratamentos.

A condição corporal média dos animais não sofreu alterações significativas entre os tratamentos, mantendo-se próxima do escore três durante todo o 
experimento, provavelmente devido às taxas de GMD não terem sido muito elevadas. Os escores médios obtidos, ao final do experimento, foram de 3,1; 3,0 e 2,9 para STP, SAS e SS, respectivamente. A velocidade de ganho de peso é um dos fatores determinantes de uma maior ou menor deposição de gordura, e ganhos moderados em animais jovens permitem apenas o crescimento e não uma mudança acentuada na condição corporal.

A tabela 3 apresenta os resultados econômicos do experimento. A suplementação adicionou um custo de 111 e $64 \%$ nos custos totais da pastagem. O tratamento SAS apresentou uma boa relação entre a produção animal ha ${ }^{-1} \mathrm{e} o$ custo adicional da suplementação. Isto possibilitou uma receita líquida direta 19\% superior ao tratamento STP. A relação renda bruta adicional / custos adicionais da suplementação demonstrou que a cada real investido retornaram 0,98 e 1,13 reais para STP e SAS, respectivamente. No tratamento STP, foram perdidos 0,04 reais a cada real gasto com suplemento. Por proporcionar mais eficiente utilização da área de pastagem com menor custo, a suplementação poderá ser uma estratégia viável para o produtor. Além disso, a maior carga animal possibilitada pela suplementação pode ser considerada um fator econômico, uma vez que a área de pastagem a

Tabela 3 - Custo total, produção animal, renda bruta e receita líquida por hectare de pastagem de aveia e azevém sob pastejo contínuo com bezerras de corte submetidas a diferentes períodos de suplementação energética.

\begin{tabular}{|c|c|c|c|c|}
\hline \multirow[t]{2}{*}{ Componentes do custo } & \multirow{2}{*}{$\begin{array}{l}\text { Quantidade } \\
\text { ha }^{-1}\end{array}$} & STP & SAS & SS \\
\hline & & \multicolumn{3}{|c|}{ 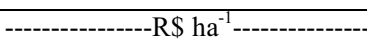 } \\
\hline Semente azevém & $35 \mathrm{~kg}$ & 12,60 & 12,60 & 12,60 \\
\hline Semente aveia & $85 \mathrm{~kg}$ & 18,70 & 18,70 & 30,60 \\
\hline Calcário & $1000 \mathrm{~kg}$ & 26,00 & 26,00 & 26,00 \\
\hline Semeadura/Adubação & $0,75 \mathrm{~kg}$ & 13,41 & 13,41 & 13,41 \\
\hline Adubos & $200 \mathrm{~kg}$ & 80,00 & 80,00 & 80,00 \\
\hline Preparo do solo & $1,2 \mathrm{hs}$ & 20,56 & 20,56 & 20,56 \\
\hline Adubação de cobertura & $0,6 \mathrm{hs}$ & 8,69 & 8,69 & 8,69 \\
\hline Mão de obra auxiliar & $0,84 \mathrm{hs}$ & 0,94 & 0,94 & 0,94 \\
\hline Uréia & $260 \mathrm{~kg}$ & 109,20 & 109,20 & 109,20 \\
\hline Suplemento & & 392,81 & 239,59 & -------- \\
\hline Beneficiamento ração & & 34,37 & 20,96 & -------- \\
\hline Transporte ração & & 0,68 & 0,68 & -------- \\
\hline Cochos & & 2,10 & 2,10 & -------- \\
\hline Arrendamento & & 21,88 & 21,88 & 43,75 \\
\hline Vermífugo & & 17,60 & 16,37 & 11,62 \\
\hline Sal comum & & 4,54 & 4,02 & 2,85 \\
\hline Monensina sódica & & 11,34 & 10,04 & 7,13 \\
\hline Custo total( $\mathrm{R} \$$ ha $\left.^{-1}\right)^{*}$ & & 775,42 & 605,75 & 333,58 \\
\hline Prod.animal $\left(\mathrm{kg} \mathrm{ha}^{-1}\right)$ & & 627,00 & 540,00 & 359,00 \\
\hline Renda bruta $\left(\mathrm{R} \$ \mathrm{ha}^{-1}\right)^{* *}$ & & 940,50 & 810,00 & 538,50 \\
\hline Receita líquida ( $\left.\mathrm{R} \$ \mathrm{ha}^{-1}\right)$ & & 165,08 & 204,25 & 204,92 \\
\hline
\end{tabular}

* Preços dos insumos atualizados em outubro de 2000

** Obtido pela venda do ganho de peso a $\mathrm{R} \$ 1,50 / \mathrm{kg}$ vivo. ser implantada pode ser reduzida para dar suporte a um mesmo número de animais.

\section{CONCLUSÕES}

A suplementação energética, em pastagem de aveia e azevém, mostrou efeito aditivo, aumentando o ganho individual e substitutivo, aumentando a carga animal suportada pela pastagem.

A cada sete a oito $\mathrm{kg}$ de suplemento energético consumido em pastagens de inverno é possível obter $1,0 \mathrm{~kg}$ de peso vivo adicional em relação à utilização apenas da pastagem.

Para a recria de novilhas de corte em pastagem cultivada de aveia e azevém, durante o primeiro inverno pós-desmama, o uso exclusivo de pastagem e a suplementação energética até o final de setembro, são alternativas economicamente viáveis.

\section{REFERÊNCIAS BIBLIOGRÁFICAS}

ASSMANN, A.L. et al. Efeito de diferentes níveis de suplementação com milho no ganho de peso de novilhos em pastejo, Porto Alegre, RS,1999. In: REUNIÃO ANUAL SOCIEDADE BRASILEIRA DE ZOOTECNIA, 1999, Porto Alegre, RS. Anais... Porto Alegre : SBZ, 1999. p.19.

BERETTA, V.; LOBATO, J.F.P. Sistema um ano de produção de carne: avaliação de estratégias alternativas de alimentação hibernal de novilhas de reposição. Rev Soc Bras Zoot, Viçosa, v.27, n.1, p.157-163, 1998.

BROWN, D. Methods of surveying and measuring vegetation. Hurley, Berkshire : Commonwealth Bureau of Pasture and Field Crops, 1954. 223 p. (Bulletin 42)

FRIZZO, A. et al. Efeito de diferentes níveis de suplementação energética no desempenho de bezerras em pastejo, Viçosa, MG, 2000. In: REUNIÃO ANUAL DA SOCIEDADE BRASILEIRA DE ZOOTECNIA, 2000, Viçosa, MG. Anais... Viçosa : SBZ, 2000. CD-Rom.

GÓMEZ, P.O.; GARDNER, A.; VERDE. Efecto de diferentes disponibilidades de pasto y níveles de suplementación sobre la ganancia de peso por animal y por hectárea em novillos de pastoreo. Balcarce : Dpto. Producción Animal, INIA, 1981. 15p. (Relatorio Técnico).

LOWMAN, B.G.; SCOTT, N.; SOMERVILLE, S. Condition scoring beef cattle. Edinburgh : East of Scotland College of Agriculture, 1973. 8p.

MIERES, J.M. Tipo de suplemento y su efecto sobre el forraje. In: MARTINS, D.V. (ed). Suplementacion estratégica para el engorde de ganado. Montevideo : Dpto. Producción Animal, INIA, 1997. 11p. (Serie Técnica 83). 
MORENO, J.A. Clima do Rio Grande do Sul. Porto Alegre: Secretaria da Agricultura do Rio Grande do Sul, 1961 .41p.

NATIONAL RESEARCH COUNCIL. Nutrient requirement of beef cattle. Washington : National Academy, 1996. 242p.

OFICIALDEGUI, R. Suplementacion estrategica de vacunos. In: ___ Seleccion de temas agropecuarios. Buenos Aires : Hemisferio Sur, 1991. p.103-128.

QUADROS, F.L.F. de; MARASCHIN, G.E. Desempenho animal em misturas de espécies forrageiras de estação fria. Pesquisa Agropecuária Brasileira, Brasília, v.22, n.5, p.535-541, 1987.
RESTLE, J. et al. Eficiência e desempenho de categorias de bovinos de corte em pastagem cultivada de inverno. Brasília, DF. In: REUNIÃO ANUAL DA SOCIEDADE BRASILEIRA DE ZOOTECNIA, 1995, Brasília. Anais... Brasília : SBZ, 1995. p.591-594.

ROCHA, M.G. Desenvolvimento e características de produção de novilhas de corte primíparas aos dois anos de idade. 1997. 247f. Tese (Doutorado em AgronomiaZootecnia) - Programa de Pós-graduação em Agronomia, Universidade Federal do Rio Grande do Sul.

TILLEY, J.M.A.; TERRY, R.A.A. Two stage technique for the "in vitro" digestion of forage crops. Journal of British Grassland Society, Hurley, v.18, n.2, p.104-111, 1963. 